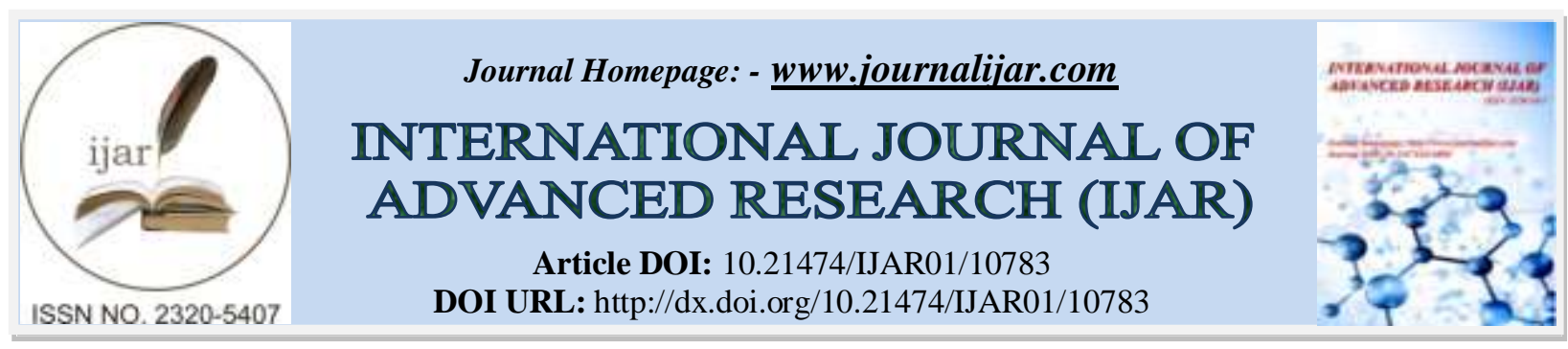

RESEARCH ARTICLE

\title{
ANALYSIS OF BIOACTIVE COMPOUNDS FROM AMARANTHUS HYBRIDUS STEM BY GAS CHROMATOGRAPHY AND MASS SPECTROSCOPY
}

Lavanya.T, Shankar Monica and Rangasamy Kavitha

Department of Biochemistry, Bharathiar University, Coimbatore, Tamil Nadu India.

\section{Manuscript Info}

\section{Manuscript History}

Received: 10 February 2020

Final Accepted: 12 March 2020

Published: April 2020

Key words:-

Amaranthus Hybridus, GC-MS

Analysis, Hexane, Stem Extract

\begin{abstract}
The main objective of the present study was to characterize the phytochemicals from the stem of Amaranthus hybridus. The shade dried stem were powdered and subjected to Soxhlet extaction with nhexane. The extract obtained was characterized by Gas chromatography-Mass spectrometry. Results revealed that different types of high and low molecular weight chemical entities with varying quantities present in the extracts. The most prevailing compounds were identified as Glycerol 1-myristate, Heneicosane, Cyclohexadecane, Hexadecane, Malonic acid, 3-methylpentyl undecyl ester 2Methylhexacosane, Eicosane, -(+)-Ascorbic acid 2,6-dihexadecanoate, Octacosane trans-13-Octadecenoic acid, 9,12-Octadecadienoic acid methyl ester, and Palmitic acid. These chemical compounds are considered biologically and pharmacologically important. It is concluded that the hexane extract of Amaranthus hybridus stem possess medicinal value as well as pharmacological activities.
\end{abstract}

Copy Right, IJAR, 2020,. All rights reserved.

\section{Introduction:-}

Plants are the traditional sources for many chemicals and they are used as pharmaceuticals, fragrances, food colors and flavors in different countries and in India. Herbal medicines and their derivative products were prepared from crude plant extracts, which contain a complex mixture of different phytochemical constituents. The chemical properties of these phytoconstituents differ considerably among different species [1]. It is been proved the potential of phenolic compounds as chemo preventive agents against chronic diseases associated to oxidative stress through an array of actions including anti-oxidant, anti-inflammatory, anti-hypertensive and anti-atherosclerotic activities [2]. Amaranthus is a common name for any flowering plant with blossoms that do not readily fade when picked and it belongs to the family Amaranthaceae. Most of the Amaranthus are found in tropics and it is cultivated in many parts of the world. They are herbs of shrubs with simple leaves and flowers in heads or spikes [3]. Amaranthus plants (Amaranthaceae) are spread throughout the world, growing under a wide range of climatic conditions and they are known to produce useful feed and food products. The leaves of amaranth constitute rich source of protein, carotenoids, vitamin $\mathrm{C}$, and dietary fiber minerals like calcium, iron, zinc, magnesium and Phosphorus [4]. Amaranthus spp. are a group of versatile food crops that consist of 60 species, of which three species are grown for edible grains and 17 species are grown for edible leaves. Amaranthus leaves are used in many countries from Africa, where they are consumed in the form of infusions, salads, soups, sauces and they are mixed with other vegetables or legumes [5]. The color of Amaranthus leaf and stalk varies from red to green, and that of the seed ranges from black to white. Highly pigmented vegetables or fruits such as anthocyanin-rich vegetables usually have higher nutritional value compared to other species of the same plant as found by [6]. Amaranthus seeds have $30 \%$ protein content 
which is higher than rice, rye and sorghum [7]. It is a rich source of essential amino acids [8]. Amaranth flour is suitable for patients with gluten allergy and plasma lipid profile positively affected after amaranth consumption [9]. Amaranthus seeds are used as an important source of natural antioxidants due to the presence of betacyanins. Also in amaranth seed the inhibitory peptides against dipeptidyl peptidase IV (DPPIV) activity have been identified by [10]. Furthermore, hypocholesterolaemic properties also reported in amaranth seeds due to the presence of squalene, an unsaturated hydrocarbon [11]. Vegetable amaranth is a good source of minerals, vitamins, phenolics, and carotenoids; it also contains betalains, a nitrogen containing group of natural pigments, as well as proteins and fibers. Those secondary metabolites or natural antioxidants are involved in defenses against several diseases like cancer, atherosclerosis, arthritis, cataracts, emphysema, and retinopathy, neuro-degenerative and cardiovascular diseases [12]. It was reported that the content of polyphenols in different amaranth seed varieties were influenced by many factors including genotype, climatic and environmental conditions, experimental sites and seasons [13]. Amaranthaceae are mostly distributed in tropical but also in temperate regions. About 18 genera and over 50 species have been reported from India [14]. However, the bio active peptide constituents of most species remain largely unexplored. In traditional medicine crude extracts from natural plants have been used to treat various ailments. One of them is Amaranthus spp. though its complete therapeutic uses are still unexplored. Recently scientific reports revealed the nutraceutical properties, composition, antioxidant properties, applications, and processing of Amaranth spp. which indicating the increasing scientific interest to know the health promoting benefits of Amaranthus spp. [15]. The present study was carried out to identify the phytocompounds in stem of Amaranthus hybridus native to India. A. hybridus contains some quality of alkaloids and the edible part is used in the treatment of intestinal bleeding, diarrhea and excessive menstruation.

\section{Materials and Methods:- Plant material:}

The plant Amaranthus hybridus was collected from vegetable market, Coimbatore, Tamil Nadu. India. It was authenticated by the Botanical Survey of India, Coimbatore Tamil Nadu, India. . The voucher number is BSI/SRC/5/23/2019/Tech/3062.

\section{Preparation of extract:}

Plant was washed with distilled water and it was shade dried in darkness at room temperature. Stem part from the Amaranthus hybridus was collected for the study. Dried Stem parts were cut into small pieces and blended into uniform dry powder. About $20 \mathrm{~g}$ of stem powder was mixed with $200 \mathrm{ml}$ of Hexane. The mixture was kept on the Soxhlet apparatus at $40{ }^{\circ} \mathrm{C}$ for $72 \mathrm{hrs}$. The concentrated stem extract was stored in an airtight container and kept in a cool, dark and dry place. These samples were employed for GC/ MS analysis

\section{Gas chromatography and Mass spectroscopic (GC-MS) Analysis:}

GC-MS analysis was carried out on a GC CLARUS SQ 8 C Perkin Elmer system comprising a gas chromatograph interfaced to a mass spectrometer (GC-MS) instrument employing the following conditions: operating in electron impact mode at $70 \mathrm{eV}$; Helium (99.999\%) was used as carrier gas at a constant flow of $1 \mathrm{ml} / \mathrm{min}$ and an injection volume of 1 microlitre was employed. The identification of the phytoconstituents was based on comparison of mass spectra, the retention index, and National Institute of Standards and Technology Library (NIST).

\section{Results and Discussion:-}

Vegetables and fruits are very important for human health because they are rich in nutrients. Leafy vegetables are not only good sources of minerals but also they are source of vitamins, antioxidants and pigments [16]. The analysis and extraction of plant material play an important role in the development, modernization and quality control of herbal formulations. Extraction is an important step in the discovery of bioactive components from plant material. Selection of the analytical strategy for extracting secondary metabolites in plant materials depends on the nature of the sample and the analyte [17]. Solvent extractions are the most commonly used procedures to prepare extracts from plant materials. There are different methods for extracting compounds from fresh vegetable foods. Conventional solvents as methanol and hexane are recognized for providing high extraction yields [18]. In the present study bioactive compounds present in hexane extract of A. Hybridus stem was evaluated by Gas chromatography and Mass spectrometry. GC-MS method used for the analysis of the obtained extracts can be an interesting tool for testing the amount of some active principles in herbs used in cosmetic, drugs, pharmaceutical or food industry [1]. The mass spectrometer analyzed the compounds eluted at different times to identify the nature and structure of the compounds. The large compound fragments into smaller compounds giving rise to appearance of 
peaks at different $\mathrm{m} / \mathrm{z}$ ratios. These mass spectra are fingerprint of compounds which can be identified from the data library. The gas chromatogram shows the relative concentrations of various compounds getting eluted as a function of retention time in minutes while the relative concentrations of the components present in the extract is indicated by the peak heights. [19]. The active principles with their \% peak area and biological activity in hexane extract of stem of A. hybridus are shown in table 2 and figure 1. Forty compounds have been identified in the hexane extract of Amaranthus hybridus stem based on library data (NIST and WILEY) of corresponding compounds. The most prevailing compounds were identified as, Glycerol 1-myristate, Heneicosane, Cyclohexadecane, Hexadecane, Malonic acid, 3-methylpentyl undecyl ester, 2-Methylhexacosane, Eicosane, -(+)-Ascorbic acid 2,6dihexadecanoate, Octacosane trans-13-Octadecenoic acid, 9,12-Octadecadienoic acid methyl ester, Palmitic Acid, Phthalic acid, di (2 - propyl pentyl) ester, Docosyl penta fluoro propionate. Previous studies revealed that Amaranthus hybridus are rich in phenolic compounds whose biological activities are well established. Amaranth oil is an effective natural antioxidant supplement since it contains high content of unsaturated fatty acids and squalene [20]. Also it is known that Amaranthus spp. is a promising source of valuable nutritional components. The seeds of Amaranthus spp are a good substitute for cereals since they contain highly unsaturated oil, squalene, tocopherols and gluten-free proteins. The leafy vegetables are rich in dietary antioxidants and other micro constituents. The leaves of amaranth possess high antioxidant activity comparing with many other traditional green leafy vegetables, they are also a good source of iron and provitamin A [13]. The presence of palmitic and linoleic acids in amaranthus spp.(A. hybridus and A. hypochondriacus cvs Cristalina and Nutrisol) was reported in previous studies. Linoleic ethyl esters was present only in A. hybridus and A. hypochondriacus cvs Cristalina and Nutrisol, while oleic acid ethyl ester was only present in A. hypochondriacus cvs Cristalina and Nutrisol. Butyl ester of palmitic and stearic acid were detected in all samples analyzed. Stigmasterol, an important phytosterol, was detected in higher abundance in the wild species A. powellii, followed by A. hypochondriacus cvs Cristalina, and A. hybridus. Squalene, an unsaturated hydrocarbon, was detected in all samples but interestingly the highest abundance was detected in A. cruentus. [11]. In the present study hexane extract of A. hybridus stem screened for phytochemicals and the results showed (Table 1) the presence of phytochemicals namely alkaloids, flavonoids and phenols. It was reported that compounds such as flavonoids are responsible for the radical scavenging effects of most plants. Phenolic compounds have also been known as antioxidant agents, which act as free radical terminators and have shown medicinal activity as well as exhibiting physiological functions [21].

\section{Conclusion:-}

The present study demonstrates the identification of phytocompounds from the A. hybridus stem. GC-MS results revealed the presence of forty different compounds including Ascorbic acid. It could be concluded that inclusion of A. hybridus into the diet may help overcoming various nutritional problems. However, further studies are needed to be carried out for compound isolation and their pharmacological action.

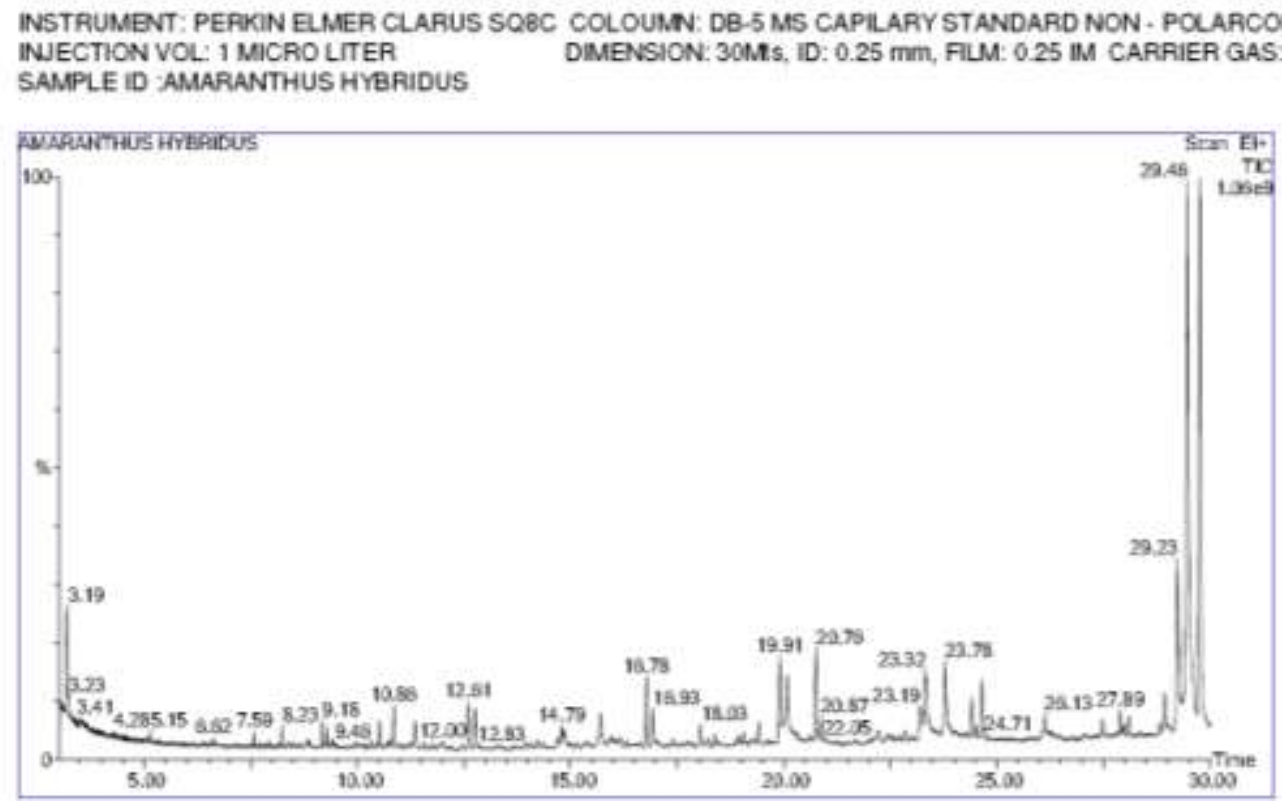

Figure 1:- GC-MS Chromatogram of Hexane extract of Amaranthus hybridus Stem. 
Table 1:- Phytochemical screening from hexane extract of Amaranthus hybridus stem.

\begin{tabular}{|l|l|}
\hline Phytochemicals & Hexane extract \\
\hline Alkaloids & + \\
\hline Flavonoids & + \\
\hline Phenols & + \\
\hline Anthraquinones & - \\
\hline Steroids & - \\
\hline Terpenoids & - \\
\hline Tannins & - \\
\hline Saponins & - \\
\hline
\end{tabular}

Table 2:- Phytocomponents identified from the hexane extract of Amaranthus hybridus stem.

\begin{tabular}{|c|c|c|c|c|c|}
\hline S.No & RT & Name of the Compound & Mol.Wt & \begin{tabular}{|l|} 
Mol. \\
Formula \\
\end{tabular} & $\begin{array}{l}\text { Peak } \\
\text { area } \%\end{array}$ \\
\hline 1 & 3.043 & n-Hexane & 86 & $\mathrm{C}_{6} \mathrm{H}_{14}$ & 2.769 \\
\hline 2 & 3.193 & N,N'-Bis(2,6-dimethyl-6-nitrosohept-2-en-4-one) & 169 & $\mathrm{C}_{18} \mathrm{H}_{30} \mathrm{~N}_{2} \mathrm{O}_{4}$ & 6.693 \\
\hline 3 & 3.389 & Pentane, 3-methyl- & 86 & $\mathrm{C}_{6} \mathrm{H}_{14}$ & 0.754 \\
\hline 4 & 3.439 & Glycerol 1-myristate & 302 & $\mathrm{C}_{17} \mathrm{H}_{34} \mathrm{O}_{4}$ & 0.426 \\
\hline 5 & 3.514 & Cyclobutylcarboxamide, N-methallyl & 139 & $\mathrm{C}_{8} \mathrm{H}_{13} \mathrm{NO}$ & 3.733 \\
\hline 6 & 3.794 & Furan, tetrahydro-2-methyl- & 160 & $\mathrm{CH}_{3} \mathrm{C}_{4} \mathrm{H}_{70}$ & 0.477 \\
\hline 7 & 3.814 & Levulinic acid, 5-bromo-3,3-dimethyl & 258 & $\mathrm{C}_{7} \mathrm{H}_{11}$ & 0.517 \\
\hline 8 & 3.874 & Tetrahydropyran & 86 & $\mathrm{C}_{5} \mathrm{H}_{10} \mathrm{O}$ & 0.636 \\
\hline 9 & 3.984 & 2-Propanone, methylhydrazone & 86 & $\mathrm{C} 4 \mathrm{H}_{10} \mathrm{~N}_{2}$ & 0.766 \\
\hline 10 & 10.526 & 1-Iodo-2-methylundecane & 296 & $\mathrm{C}_{12} \mathrm{H}_{25} \mathrm{I}$ & 0.440 \\
\hline 11 & 10.857 & 2,4-Di-tert-butylphenol & 206 & $\mathrm{C}_{14} \mathrm{H}_{22} \mathrm{O}$ & 0.674 \\
\hline 12 & 11.357 & Heneicosane & 296 & $\mathrm{C}_{21} \mathrm{H}_{44}$ & 0.578 \\
\hline 13 & 12.607 & Cyclohexadecane & 224 & $\mathrm{C}_{12} \mathrm{H}_{24} \mathrm{O}_{2}$ & 0.931 \\
\hline 14 & 12.767 & Hexadecane & 226 & $\mathrm{C}_{16} \mathrm{H}_{34}$ & 0.775 \\
\hline 15 & 14.793 & Dodecane, 2,6,11-trimethyl- & 156 & $\mathrm{C} 15 \mathrm{H} 32$ & 0.474 \\
\hline 16 & 14.858 & Malonic acid, 3-methylpentyl undecyl ester & 200 & $\mathrm{C}_{12} \mathrm{H}_{24} \mathrm{O}_{2}$ & 0.397 \\
\hline 17 & 15.708 & 2-Methylhexacosane & 351 & $\mathrm{C}_{27} \mathrm{H}_{56}$ & 0.991 \\
\hline 18 & 16.789 & 3-Eicosene, (E)- & 210 & $\mathrm{C}_{20} \mathrm{H}_{40}$ & 1.463 \\
\hline 19 & 16.929 & Eicosane & 343 & $\mathrm{C}_{20} \mathrm{H}_{42}$ & 0.759 \\
\hline 20 & 18.049 & 1,2-Benzenedicarboxylic acid, bis(2-methylpropyl) ester & 278 & $\mathrm{C}_{16} \mathrm{H}_{22} \mathrm{O}_{4}$ & 0.414 \\
\hline 21 & 19.065 & Heptadecane, 9-octyl- & 352 & $\mathrm{C}_{25} \mathrm{H}_{52}$ & 0.301 \\
\hline 22 & 19.410 & $\begin{array}{l}\text { Cyclopropanebutanoic acid, 2-[[2-[[2-[(2- } \\
\text { pentylcyclopropyl)methyl] cyclopropyl]methyl]cycl } \\
\text { opropyl]methyl]-, methyl ester }\end{array}$ & 374 & $\mathrm{C}_{25} \mathrm{H}_{42} \mathrm{O}_{2}$ & 0.463 \\
\hline 23 & 19.905 & Sulfabenzamide & 276 & $\mathrm{C}_{13} \mathrm{H}_{12} \mathrm{~N}_{2} \mathrm{O}_{3} \mathrm{~S}$ & 1.525 \\
\hline 24 & 20.080 & 1-(+)-Ascorbic acid 2,6-dihexadecanoate & 652 & $\mathrm{C}_{38} \mathrm{H}_{68} \mathrm{O}_{8}$ & 1.645 \\
\hline 25 & 20.760 & 1-Docosene & 308 & $\mathrm{C}_{22} \mathrm{H}_{44}$ & 1.902 \\
\hline 26 & 20.871 & Octacosane & 394 & $\mathrm{C}_{28} \mathrm{H}_{58}$ & 0.405 \\
\hline 27 & 22.226 & Behenic alcohol & 326 & $\mathrm{C}_{22} \mathrm{H}_{46} \mathrm{O}$ & 0.464 \\
\hline 28 & 23.206 & 9,12-Octadecadienoic acid, methyl ester, (E,E)- & 294 & $\mathrm{C}_{19} \mathrm{H}_{34} \mathrm{O}_{2}$ & 1.100 \\
\hline 29 & 23.327 & trans-13-Octadecenoic acid & 282 & $\mathrm{C}_{18} \mathrm{H}_{34} \mathrm{O}_{2}$ & 2.682 \\
\hline 30 & 23.782 & Octadecanoic acid, 2-(2-hydroxyethoxy)ethyl ester & 372 & $\mathrm{C}_{22} \mathrm{H}_{44} \mathrm{O}_{4}$ & 2.128 \\
\hline 31 & 24.412 & 10-Heneicosene $(\mathrm{c}, \mathrm{t})$ & 294 & $\mathrm{C}_{21} \mathrm{H}_{42}$ & 0.883 \\
\hline 32 & 24.652 & Tricosyl acetate & 382 & $\mathrm{C}_{25} \mathrm{H}_{50} \mathrm{O}_{2}$ & 1.329 \\
\hline 33 & 26.128 & $\begin{array}{l}\text { Eicosanoic acid, 2-hydroxy-1- } \\
\text { (hydroxymethyl)ethyl ester }\end{array}$ & 386 & $\mathrm{C}_{23} \mathrm{H}_{46} \mathrm{O}_{4}$ & 0.891 \\
\hline 34 & 27.473 & Disulfide, di-tert-dodecyl & 402 & $\mathrm{C}_{24} \mathrm{H}_{50} \mathrm{~S}_{2}$ & 0.446 \\
\hline 35 & 27.898 & Docosylpentafluoropropionate & 332 & $\mathrm{C}_{15} \mathrm{H}_{25} \mathrm{~F}_{5} \mathrm{O}_{2}$. & 0.477 \\
\hline
\end{tabular}




\begin{tabular}{|c|c|c|c|c|c|}
\hline 36 & 28.093 & Acetic acid n-octadecyl ester & 312 & $\mathrm{C}_{20} \mathrm{H}_{40} \mathrm{O}_{2}$ & 0.423 \\
\hline 37 & 28.934 & $\begin{array}{l}\text { 3,7,11,15,19-Pentaoxa-2,20-disilaheneicosane, } 2 \text {, } \\
\text { 2,20,20-tetramethyl- }\end{array}$ & 296 & $\mathrm{C}_{20} \mathrm{H}_{40} \mathrm{O}$ & 0.950 \\
\hline 38 & 29.229 & Palmitic Acid, TMS derivative & 328 & $\mathrm{C}_{19} \mathrm{H}_{40} \mathrm{O}_{2} \mathrm{Si}$ & 4.171 \\
\hline 39 & 29.464 & Palmitic anhydride & 494 & $\mathrm{C}_{32} \mathrm{H}_{62} \mathrm{O}_{3}$ & 16.084 \\
\hline 40 & 29.759 & Phthalic acid, di ( 2 - propyl pentyl) ester & 390 & $\mathrm{C}_{24} \mathrm{H}_{38} \mathrm{O}_{4}$ & 12.821 \\
\hline
\end{tabular}

\section{References:-}

1. Gomathi, D., Kalaiselvi, M., Ravikumar, G., Devaki, K., \& Uma, C. (2015). GC-MS analysis of bioactive compounds from the whole plant ethanolic extract of Evolvulus alsinoides (L.) L. Journal of food science and technology, 52(2), 1212-1217.

2. Del Rio, D., Rodriguez-Mateos, A., Spencer, J. P., Tognolini, M., Borges, G., \& Crozier, A. (2013). Dietary (poly) phenolics in human health: structures, bioavailability, and evidence of protective effects against chronic diseases. Antioxidants \& redox signaling, 18(14), 1818-1892.

3. Okoye, E. I. (2018). Qualitative and Quantitative Phytochemical Analysis and Antimicrobial Screening of Solvent Extracts of Amaranthus hybridus (Stem and Leaves). Chemistry Res J, 3, 9-13.

4. Ozsoy, N., Yilmaz, T., Kurt, O., Can, A., \& Yanardag, R. (2009). In vitro antioxidant activity of Amaranthus lividus L. Food Chemistry, 116(4), 867-872.

5. Jiménez-Aguilar, D. M., \& Grusak, M. A. (2017). Minerals, vitamin C, phenolics, flavonoids and antioxidant activity of Amaranthus leafy vegetables. Journal of Food Composition and Analysis, 58, 33-39.

6. Li, H., Deng, Z., Liu, R., Zhu, H., Draves, J., Marcone, M., \& Tsao, R. (2015). Characterization of phenolics, betacyanins and antioxidant activities of the seed, leaf, sprout, flower and stalk extracts of three Amaranthus species. Journal of Food Composition and Analysis, 37, 75-81.

7. Srivastava, S., Bisht, H., Sidhu, O. P., Srivastava, A., Singh, P. C., Pandey, R. M., ... \& Nautiyal, C. S. (2012). Changes in the metabolome and histopathology of Amaranthus hypochondriacus L. in response to Ageratum enation virus infection. Phytochemistry, 80, 8-16.

8. Tucker, J. B. (1986). Amaranth: the once and future crop. Bioscience 36:9-13. $59-60$.

9. J. CzerwiÅski, E. Bartnikowska, H. Leontowicz, E. Lange, M. Leontowicz, E. Katrich, S. Trakhtenberg, S. Gori nsteinOat (Avena sativa L.) and amaranth (Amaranthus hypochondriacus) meals positively affect plasma lipid profile in rats fed cholesterol-containing dietsThe Journal of Nutritional Biochemistry, 15 (2004), pp. 622-629

10. Paucar-Menacho, L. M., Peñas, E., Dueñas, M., Frias, J., \& Martinez-Villaluenga, C. (2017). Optimizing germination conditions to enhance the accumulation of bioactive compounds and the antioxidant activity of kiwicha (Amaranthus caudatus) using response surface methodology. LWT-Food Science and Technology, 76, 245-252.

11. Bojórquez-Velázquez, E., Velarde-Salcedo, A. J., De León-Rodríguez, A., Jimenez-Islas, H., Pérez-Torres, J. L., Herrera-Estrella, A., ... \& de la Rosa, A. P. B. (2018). Morphological, proximal composition, and bioactive compounds characterization of wild and cultivated amaranth (Amaranthus spp.) species. Journal of cereal science, 83, 222-228.

12. Sarker, U., \& Oba, S. (2018). Response of nutrients, minerals, antioxidant leaf pigments, vitamins, polyphenol, flavonoid and antioxidant activity in selected vegetable amaranth under four soil water content. Food chemistry, 252, 72-83

13. Kraujalis, P., Venskutonis, P. R., Kraujalienė, V., \& Pukalskas, A. (2013). Antioxidant properties and preliminary evaluation of phytochemical composition of different anatomical parts of amaranth. Plant foods for human nutrition, 68(3), 322-328.

14. Rahman, A. H. M. M., \& Gulshana, M. I. A. (2014). Taxonomy and medicinal uses on amaranthaceae family of Rajshahi, Bangladesh. Applied Ecology and Environmental Sciences, 2(2), 54-59.

15. Peter, K., \& Gandhi, P. (2017). Rediscovering the therapeutic potential of Amaranthus species: a review. Egyptian journal of basic and applied sciences, 4(3), 196-205.

16. Khanam, U. K. S., Oba, S., Yanase, E., \& Murakami, Y. (2012). Phenolic acids, flavonoids and total antioxidant capacity of selected leafy vegetables. Journal of Functional Foods, 4(4), 979-987.

17. Madan, V.K. \& Jangra, Satya \& Singh, Sushila. (2016). Effect of Extraction Techniques and Solvents on Various Phytochemicals and Antioxidant Activity of Clove (Syzygium aromaticum L.) Buds. Asian Journal of Chemistry. 28. 801-806. 10.14233/ajchem.2016.19522. 
18. López-Mejía, O. A., López-Malo, A., \& Palou, E. (2014). Antioxidant capacity of extracts from amaranth (Amaranthus hypochondriacus L.) seeds or leaves. Industrial Crops and Products, 53, 55-59.

19. Solomon A. Mamuru1, Iliya Kaigamma, Muluh E. Khan (2019) Preliminary Phytochemical Screening and GC-MS Analysis of Aqueous and Ethanolic Extracts of Amaranthus spinosus Leaves J. Nat. Prod. Resour. Volume 5 Issue 2 (2019) 213-215

20. Martirosyan, D. M., Miroshnichenko, L. A., Kulakova, S. N., Pogojeva, A. V., \& Zoloedov, V. I. (2007). Amaranth oil application for coronary heart disease and hypertension. Lipids in health and disease, 6(1), 1 .

21. Paranthaman, R Praveen kumar P, Kumaravel S (2012) GC+MS Analysis of phytochemicals and simultaneous determination of Flavanoids in Amaranthus caudate (sirukeerai) by RPhplc. J.Anal Bioanal Techniques 3:147. 